\title{
Global change drives modern plankton communities away from the pre-industrial state
}

\author{
Lukas Jonkers ${ }^{1 *}$, Helmut Hillebrand ${ }^{2,3,4}$ \& Michal Kucera ${ }^{1}$
}

\begin{abstract}
The ocean-the Earth's largest ecosystem-is increasingly affected by anthropogenic climate change ${ }^{1,2}$. Large and globally consistent shifts have been detected in species phenology, range extension and community composition in marine ecosystems ${ }^{3-5}$. However, despite evidence for ongoing change, it remains unknown whether marine ecosystems have entered an Anthropocene ${ }^{6}$ state beyond the natural decadal to centennial variability. This is because most observational time series lack a long-term baseline, and the few time series that extend back into the pre-industrial era have limited spatial coverage ${ }^{7,8}$. Here we use the unique potential of the sedimentary record of planktonic foraminifera-ubiquitous marine zooplankton-to provide a global pre-industrial baseline for the composition of modern species communities. We use a global compilation of 3,774 seafloor-derived planktonic foraminifera communities of pre-industrial age ${ }^{9}$ and compare these with communities from sediment-trap time series that have sampled plankton flux since AD 1978 (33 sites, 87 observation years). We find that the Anthropocene assemblages differ from their pre-industrial counterparts in proportion to the historical change in temperature. We observe community changes towards warmer or cooler compositions that are consistent with historical changes in temperature in $85 \%$ of the cases. These observations not only confirm the existing evidence for changes in marine zooplankton communities in historical times, but also demonstrate that Anthropocene communities of a globally distributed zooplankton group systematically differ from their unperturbed pre-industrial state.
\end{abstract}

To determine whether anthropogenic climate change has affected the marine environment beyond its natural state, it is essential to compare modern observations to a pre-industrial baseline. Because such a baseline is available for the physical state of the ocean, it has been established that, in response to global warming, the sea-surface temperature field has changed significantly since the onset of industrialization approximately 170 years ago ${ }^{1,2}$ (Fig. 1). Marine ecosystem research, on the other hand, is almost exclusively based on observations since the mid-twentieth century and the pre-industrial baseline is therefore mostly unknown. Although existing observations provide strong evidence for changes in marine ecosystems in a direction that is consistent with late-twentieth century climate change $\mathrm{e}^{3,4,10,11}$, this lack of a pre-industrial reference prevents assessing the degree to which Anthropocene marine ecosystems differ from their natural, preindustrial state ${ }^{12}$. This affects our ability to predict the effects of global change on marine ecosystem functioning and the resulting impacts on the resources that they provide to society.

Planktonic foraminifera are a globally ubiquitous group of marine zooplankton. Their distribution is primarily controlled by temperature $\mathrm{i}^{13,14}$. About 40 morphospecies are known ${ }^{15}$; they occur most abundantly in the surface mixed layer, but some species can be found alive down to several hundreds of metres ${ }^{16}$. They are unique among marine zooplankton because their calcite shells are well-preserved in marine sediments. This renders them an ideal model system to investigate the influence of global change on marine zooplankton, because seafloor sediments offer the chance to obtain an accurate picture of the composition of planktonic foraminifera communities in the past. Indeed, their skeletal remains have extensively been used to elucidate past climate and ecological changes ${ }^{17,18}$. However, the influence of anthropogenic climate change on planktonic foraminifera communities has only been investigated in very few studies with a regional focus ${ }^{7,19}$ and an assessment on a global scale is lacking.

Here we use a quality-controlled compilation of planktonic foraminifera species assemblages of pre-industrial age from seafloor sediments (see Methods) and compare these to modern (1978-2013) assemblages based on observations from moored sediment-trap time series (see Methods). The sediment samples $(n=3,754)$ cover all major ecological provinces, and almost the entire global temperature gradient, at high resolution (Fig. 1). By virtue of the sedimentation process and sediment mixing by deep-sea organisms, foraminiferal shells that are extracted from the uppermost sediment layer represent a centennially to millennially integrated assemblage before marked human influences (see Methods). The modern assemblages are based on the integration of shell flux of planktonic foraminifera over at least one year and are thus not affected by ontogeny and/or seasonality. Most of the sediment-trap sites are from the Northern Hemisphere; however, they cover the global thermal gradient and include time series spanning up to 12 years. We compare these Anthropocene assemblages with those in the sediment using a square-chord distance metric on species relative abundances (see Methods). We find that all Anthropocene communities differ from those in the nearest sediment sample and that the degree of dissimilarity scales with the temperature change since AD 1870 at each site $(r=0.53, P=0.001, n=33$; Fig. $2 \mathrm{a})$. This suggests that planktonic foraminifera communities have changed considerably since the pre-industrial period, and that they have done so in proportion to the magnitude of local temperature change. When comparing the modern species composition with the sediment samples, we find that for each modern assemblage the most similar sedimentary analogue is not the assemblage from the nearest core top, but an assemblage from a core top located elsewhere (Fig. 2b). Thus, the changes in community composition and presence of close analogues elsewhere indicate a directional shift at the community level, rather than a random reshuffling of the species forming previously unseen communities. On the basis of the difference between the modern and pre-industrial communities, we estimate that this shift equates to a median latitudinal displacement of $602 \mathrm{~km}$ (range, 45-2,557 km) since pre-industrial times (Fig. 2c).

To evaluate the direction of change in community composition, we consider the location of sedimentary assemblages with species compositions that are most similar to the Anthropocene assemblages from the sediment traps. We observe that these sediment assemblages are in most cases from warmer areas, thus confirming that the twentiethcentury community composition shows an imprint of global warming (Fig. 3). Warming signatures are found across the globe and in a range 


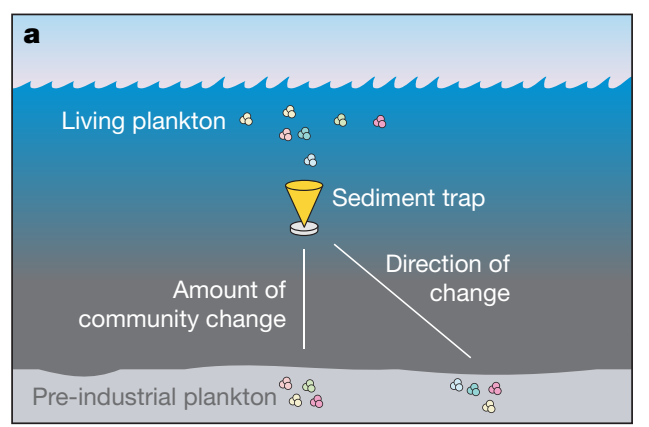

Fig. 1 | Concept of the comparison between Anthropocene and preindustrial communities. a, The integrated living planktonic foraminifera flux from sediment-trap time series is compared to the sedimentary community closest to the trap to quantify community change. The position of the most-similar sedimentary assemblage reveals the direction

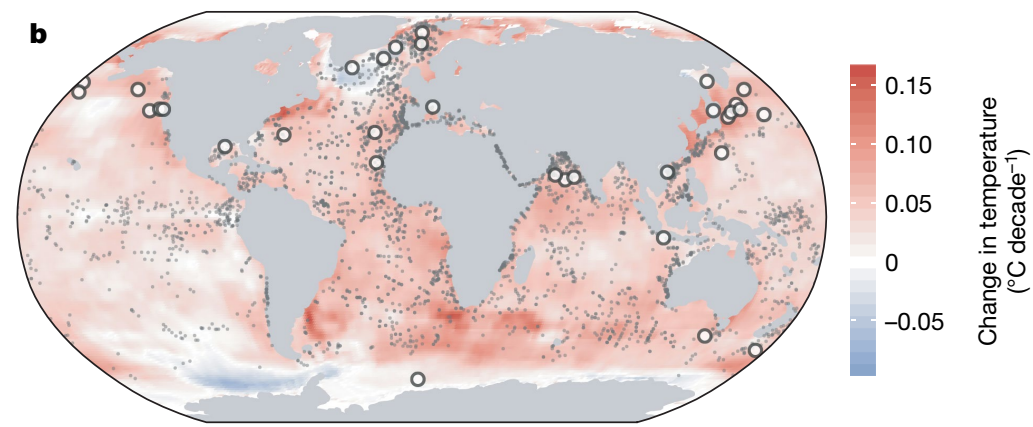

of the change. $\mathbf{b}$, Grey and white dots indicate the position of the sediment samples and sediment traps, respectively. Background shows the linear sea-surface temperature trend between 1870 and 2015 based on the Hadley Centre Sea Ice and Sea Surface Temperature dataset (HadISST) ${ }^{26}$. of environments (open ocean, coastal regions, upwelling regions, and at low and high latitudes), which indicates that species compositions have shifted worldwide. Some parts of the ocean are known to have been cooling during the Anthropocene (Fig. 1). This historical cooling has also affected the composition of Anthropocene assemblages, such that the direction of change inferred from the change in the planktonic foraminifera community is-in the large majority of cases (85\%)consistent with the observed temperature change, irrespective of whether the observed historical trend has been warming or cooling (Fig. 3). The single case in which the species composition indicates warming in a cooling area is in the North Pacific gyre, where the amount of temperature change has been negligible. Thus, we conclude that the chance of finding false warming signatures is low and that the observed pattern in community change is robust, indicating that the communities have responded to the dynamic pattern of changes in sea-surface temperatures induced by global warming. We also observe that time series that show a change in the species community that is inconsistent with historical changes in temperature, are randomly distributed throughout the observational period. Therefore, there is no trend in the degree of consistency, which suggests not only that the faunal composition departed from the pre-industrial baseline but also that it started to do so before the beginning of the sediment-trap observations in AD 1978. If we assume that the inferred community change occurred predominantly after the mid-nineteenth century onset of industrial-era warming, the observed median displacement of approximately $600 \mathrm{~km}$ translates into a displacement rate of around $40 \mathrm{~km}$ per decade. This is a conservative estimate, because it is likely that the rate of community change accelerated during the twentieth century and-although there are no comparable data on the rate of community displacement-our estimate is comparable to displacement rates of individual zooplankton species (around $100 \mathrm{~km}$ per decade $)^{3}$.

Even though the pattern of community change in the planktonic foraminifera shows a clear fingerprint of global warming, comparisons between assemblages from the plankton and from the sediment are not straightforward. By using direct observations of integrated annual flux from sediment traps, we obtained a more realistic approximation of sedimentary assemblages than indirect estimates from repeated plankton tows because the effects of ontogeny and seasonal abundance variability can be ruled out. Nevertheless, we also evaluate the effect of other potential biases on our observations, in part because some of the variance in the assemblage change remains unexplained (Fig. 2a). We rule out a temporal sampling bias due to interannual variability as, firstly, the sign of change in individual years is consistent with the longterm signal in $81-92 \%$ of the multiyear time series (Fig. $4 \mathrm{a}$ ) and, secondly, the signal is consistent in $87 \%$ of the one-year time series, which should otherwise mostly be affected by noise imposed by interannual variability. The comparisons between modern and pre-industrial assemblages could furthermore be complicated by differential preservation in the sediment ${ }^{20,21}$ and the non-uniform spatial distribution of the sediment samples. We therefore perform sensitivity tests using subsets of the data. We use depth as an indicator of potential preservation bias, as calcite dissolution increases with water depth, and choose $2,000 \mathrm{~m}$ as a level below which the assemblages could be affected by dissolution. This is a conservative separation even for the Pacific Ocean, where the lysocline is shallower than in the Atlantic Ocean ${ }^{22}$. As foraminifera can
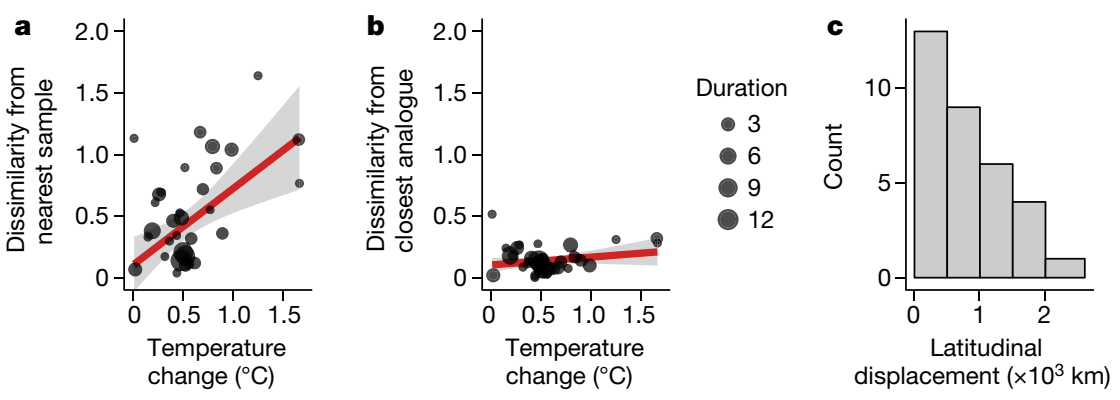

Fig. 2 Changes in planktonic foraminifera communities in response to Anthropocene sea-surface temperature change. a, Dissimilarity to the nearest sediment sample, indicative of the compositional difference between modern and pre-industrial communities, scales with the absolute historical change in temperature at the site of each trap $(n=33 ; r=0.53$, weighted by time-series duration, $P=0.001$; unweighted $r=0.48, P=0.005$ ), which suggests that species composition has changed proportionally to temperature change since pre-industrial times. b, Dissimilarity between modern and most-similar pre-industrial species communities, showing that all Anthropocene species communities have more similar analogues elsewhere (difference between $\mathbf{a}$ and $\mathbf{b}$ ), consistent with a shift of the species composition in the same direction as the temperature change. $\mathbf{a}, \mathbf{b}$, Dots are scaled to the duration of the sediment-trap time series; error envelopes show $95 \%$ confidence intervals. c, Histogram of latitudinal displacement of planktonic foraminifera communities in kilometres since pre-industrial times (see Methods). 
a

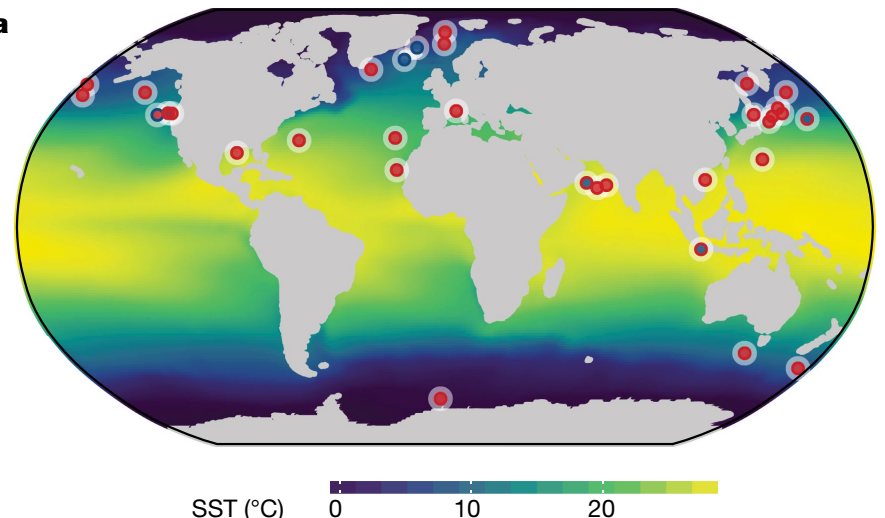

b

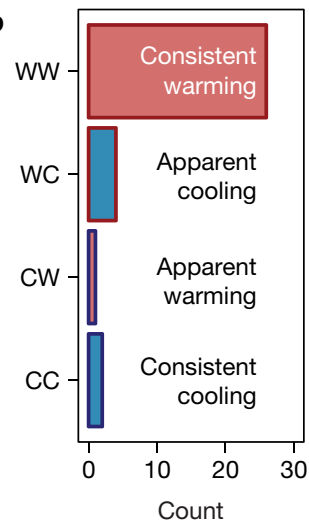

Fig. 3 | Global planktonic foraminifera communities change consistently with historical temperature trends. Planktonic foraminifera community change shows a clear predominance of warming signatures across the oceans, consistent with the known pattern of Anthropocene sea-surface temperature change. a, Spatial pattern of the direction of community change (colour fill) and the direction of the historical change in temperature (border colour); both agree in $85 \%$ of the observations
$(P<0.001$, two-sided binomial test, $n=33)$. Background colour shading shows mean sea-surface temperature (SST) ${ }^{26}$ over the observation period (1978-2013). b, Histogram of the consistency of Anthropocene community change in response to temperature change. $\mathrm{W}$ and $\mathrm{C}$ indicate warming and cooling, respectively. The first letter indicates the historical change, and the second indicates change in the species composition. be transported by ocean currents over hundreds of kilometres during their life cycle and while sinking to the seafloor ${ }^{23,24}$, we use a $250-\mathrm{km}$ threshold to separate modern samples with a far and nearby preindustrial counterpart. All four subsets show that in the majority of the cases the direction of change in species communities is consistent with historical temperature change (Fig. 4b). Finally, we also evaluated the sensitivity of our results to the effect of differences in size fractions used to determine the community composition and to the uncertainty in the observational temperature data (see Methods). These tests also confirm that the observed pattern in global planktonic foraminifera community change is robust.

We thus show that there is a globally expressed difference between pre-industrial and Anthropocene marine planktonic foraminifera communities that indicates community turnover, which is in sign and magnitude consistent with global temperature change. As such, we provide evidence in support of observations from shorter time series that lacked a characterization of community state before human influence ${ }^{3-5}$. The community change in planktonic foraminifera unambiguously shows that human influence has considerably altered their species communities across the globe. This has important implications for the calibration of palaeoclimate proxies based on planktonic foraminifera, because foraminifera that are preserved in the sediment no longer reflect oceanographic conditions above the site of deposition. We also suggest that the described shifts in planktonic foraminifera are indicative of a more-general phenomenon across marine ecosystems, in which present-day assemblages differ from historical ones in a way that reflects the change in environmental conditions since the onset of the Anthropocene. These findings place emphasis on the recent discussion on how well communities are adapted to rapid environmental change: if the potential for spatial displacement and adaptation lags behind the rate of change in the environment, modern-day assemblages may always show a trait distribution with suboptimal fitness ${ }^{25}$. Beyond single species, this lag may be especially explicit at the level of communities given the time needed to establish new interaction networks. This, in turn, has potentially large effects on ecosystem functioning as well as on the services that marine ecosystems deliver to society. a

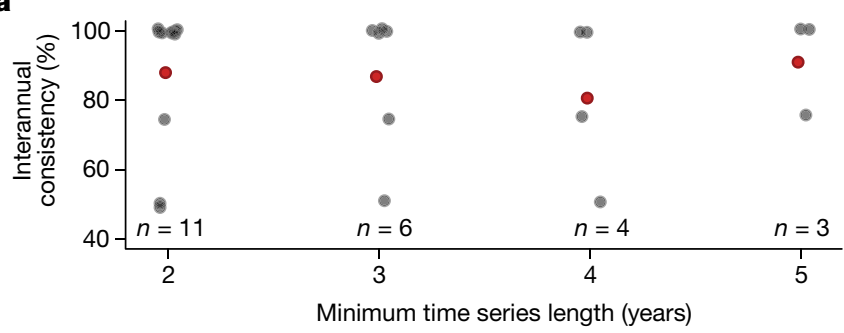

Fig. 4 Robustness of the sign of change in planktonic foraminifera community composition. a, Proportion of individual years in multi-year time series that show a community change consistent with the long-term mean (grey dots, jittered for visibility, show individual time series; red dots show the mean). We restricted this analysis to time series with a duration of at least two years and years without gaps longer than three months. On average, $81-92 \%$ of the individual years are consistent with the longterm average and this consistency is robust against time-series length and b

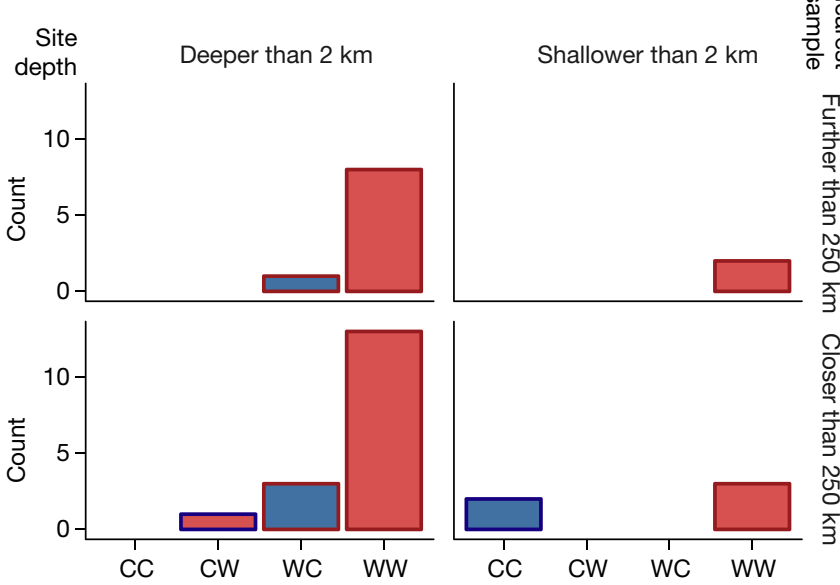

imputation. This indicates that our observations are not biased by single anomalous years but instead reflect a robust change in global species composition. b, Sensitivity tests show that our results are not dependent on differential preservation and non-uniform spatial distribution of the sediment samples, as each subset is dominated by changes in the species community that are consistent in sign with historical changes in temperature. Labels are as in Fig. 3b. 


\section{Online content}

Any methods, additional references, Nature Research reporting summaries, source data, statements of data availability and associated accession codes are available at https://doi.org/10.1038/s41586-019-1230-3.

Received: 1 August 2018; Accepted: 26 April 2019; Published online 22 May 2019.

1. IPCC. Climate Change 2013: The Physical Science Basis (eds Stocker, T. F. et al.) (Cambridge Univ. Press, 2013)

2. Abram, N. J. et al. Early onset of industrial-era warming across the oceans and continents. Nature 536, 411-418 (2016).

3. Poloczanska, E. S. et al. Global imprint of climate change on marine life. Nat. Clim. Change 3, 919-925 (2013).

4. Beaugrand, G., McQuatters-Gollop, A., Edwards, M. \& Goberville, E. Long-term responses of North Atlantic calcifying plankton to climate change. Nat. Clim. Change 3, 263-267 (2013).

5. Hoegh-Guldberg, O. \& Bruno, J. F. The impact of climate change on the world's marine ecosystems. Science 328, 1523-1528 (2010).

6. Waters, C. N. et al. The Anthropocene is functionally and stratigraphically distinct from the Holocene. Science 351, aad2622 (2016).

7. Field, D. B., Baumgartner, T. R., Charles, C. D., Ferreira-Bartrina, V. \& Ohman, M. D. Planktonic foraminifera of the California Current reflect 20th-century warming. Science 311, 63-66 (2006).

8. Spielhagen, R. F. et al. Enhanced modern heat transfer to the Arctic by warm Atlantic Water. Science 331, 450-453 (2011).

9. Siccha, M. \& Kucera, M. ForCenS, a curated database of planktonic foraminifera census counts in marine surface sediment samples. Sci. Data 4, 170109 (2017).

10. Rosenzweig, C. et al. Attributing physical and biological impacts to anthropogenic climate change. Nature 453, 353-357 (2008).

11. Hillebrand, $H$. et al. Biodiversity change is uncoupled from species richness trends: consequences for conservation and monitoring. J. Appl. Ecol. 55 169-184 (2018).

12. Gonzalez, A. et al. Estimating local biodiversity change: a critique of papers claiming no net loss of local diversity. Ecology 97, 1949-1960 (2016).

13. Morey, A. E., Mix, A. C. \& Pisias, N. G. Planktonic foraminiferal assemblages preserved in surface sediments correspond to multiple environment variables. Quat. Sci. Rev. 24, 925-950 (2005).

14. Bé, A. W. H. \& Tolderlund, D. S. in The Micropaleontology of Oceans (eds Funnell, B. M. \& Riedel, W. R.) Ch. 6, 105-149 (Cambridge Univ. Press, 1971).]

15. Morard, R. et al. Surface ocean metabarcoding confirms limited diversity in planktonic foraminifera but reveals unknown hyper-abundant lineages. Sci. Rep. 8, 2539 (2018).

16. Rebotim, A. et al. Factors controlling the depth habitat of planktonic foraminifera in the subtropical eastern North Atlantic. Biogeosciences 14 827-859 (2017).

17. CLIMAP Project Members. Seasonal Reconstruction of the Earth's surface at the Last Glacial Maximum. Map and Chart Series MC-36 (ed. Mclntyre, A.) (Geological Society of America, 1981).

18. Kucera, M. et al. Reconstruction of sea-surface temperatures from assemblages of planktonic foraminifera: multi-technique approach based on geographically constrained calibration data sets and its application to glacial Atlantic and Pacific Oceans. Quat. Sci. Rev. 24, 951-998 (2005).

19. Ruddiman, W. F., Tolderlund, D. S. \& Bé, A. W. H. Foraminiferal evidence of a modern warming of the North Atlantic Ocean. Deep Sea Res. 17, 141-155 (1970).

20. Berger, W. H. Planktonic Foraminifera: selective solution and paleoclimatic interpretation. Deep Sea Res. 15, 31-43 (1968).

21. Berger, W. H. Planktonic Foraminifera: selective solution and the lysocline. Mar. Geol. 8, 111-138 (1970).

22. Archer, D. E. An atlas of the distribution of calcium carbonate in sediments of the deep sea. Glob. Biogeochem. Cycles 10, 159-174 (1996).

23. von Gyldenfeldt, A.-B., Carstens, J. \& Meincke, J. Estimation of the catchment area of a sediment trap by means of current meters and foraminiferal tests. Deep Sea Res. 47, 1701-1717 (2000).

24. van Sebille, E. et al. Ocean currents generate large footprints in marine palaeoclimate proxies. Nat. Commun. 6, 6521 (2015).

25. Enquist, B. J. et al. in Advances in Ecological Research Vol. 52 (eds Pawar, S. et al.) 249-318 (Academic, 2015).

26. Rayner, N. A. et al. Global analyses of sea surface temperature, sea ice, and night marine air temperature since the late nineteenth century. J. Geophys. Res. 108, 4407 (2003).

Acknowledgements We thank R. Reuter for help with foraminifera analysis and acknowledge funding by the Volkswagen Stiftung for the MarBAS (Marine Biodiversität-Analyse über zeitliche und räumliche Skalen) project as well as by the Deutsche Forschungsgemeinschaft (DFG, German Research Foundation) through Germany's Excellence Strategy (EXC-2077, grant no 390741603). M.K. was funded through DFG-Research Center/Cluster of Excellence 'The Ocean in the Earth System'.

Reviewer information Nature thanks Andrew J. Fraass, Anthony Richardson and the other anonymous reviewer(s) for their contribution to the peer review of this work.

Author contributions L.J. and M.K. designed research. L.J. compiled and analysed the data. All authors discussed the results and contributed to the writing of the manuscript.

Competing interests The authors declare no competing interests.

\section{Additional information}

Extended data is available for this paper at https://doi.org/10.1038/s41586-

019-1230-3.

Supplementary information is available for this paper at https://doi.org/ 10.1038/s41586-019-1230-3.

Reprints and permissions information is available at http://www.nature.com/ reprints.

Correspondence and requests for materials should be addressed to L.J.

Publisher's note: Springer Nature remains neutral with regard to jurisdictional claims in published maps and institutional affiliations.

() The Author(s), under exclusive licence to Springer Nature Limited 2019 


\section{METHODS}

Data. Quality-controlled and taxonomically harmonized core top assemblage data were obtained from the ForCenS dataset ${ }^{9}$. Samples for which species groups and species forms (for example, differently coiled morphospecies) were not resolved were excluded $(n=128)$ and in cases in which multiple samples were available for the same location $(n=303)$, one was randomly selected. The modern assemblages are derived by integrating shell flux time series from moored sediment traps (Extended Data Table 1). Sediment-trap time series selection criteria followed a previous study ${ }^{27}$ with the additional constraint that only time series with full taxonomic resolution (considering the same range of species as in the sediment samples) were included. The taxonomy of the time series was harmonized with that of the core top data following previously published criteria ${ }^{9}$. To eliminate the effect of seasonality in the flux when deriving the flux-weighted assemblages, only time series with a length of at least 345 days were analysed. Gaps in the time series were linearly interpolated or, where possible, filled using a smoothed version (LOESS, span 0.1) of the multiyear median flux pattern. To make full use of the available data and to estimate the influence of interannual flux variability, annual assemblages were calculated for each year for which at least three months of data were available, using the smoothed flux pattern to impute missing values. As is common in palaeo-ecological studies, the dissimilarity between the pre-industrial and modern species assemblages was assessed using square chord distance between species relative abundances because this metric has been shown to be most effective in identifying analogues in microfossil datasets ${ }^{28}$.

Various planktonic foraminifera morphospecies consist of multiple, genetically different, cryptic species ${ }^{29}$. To minimize the effect of differences in the ecology of cryptic species, dissimilarity was determined regionally ${ }^{18}$ such that sediment samples with the most-similar assemblages were sought only within the same oceanic basin as the analysed sediment-trap time series.

The latitudinal displacement of the species communities was estimated from the dissimilarity between the modern assemblage and the nearest sediment assemblage. We used linear relationships between dissimilarity and the latitudinal component of distance derived from the sediment data. To account for regional variability in spatial trends in biodiversity, we established these relationships for each sediment trap site, using the latitudinal distance from the nearest sediment sample within a radius of $5,000 \mathrm{~km}$. Regression models were forced through the origin (because at zero distance, the assemblages should be identical) and established for the first 2,500 km latitudinal distance, as this is the distance at which dissimilarity tends to saturate and the distance-dissimilarity relationship changes slope (see example in Extended Data Fig. 2).

Sea-surface temperature data are from the HadISST dataset ${ }^{26}$. We use data from the $1870-1899$ period within a $100-\mathrm{km}$ radius around each sampling location to derive an estimate of the mean temperature. The direction of historical change in temperature for each sediment-trap location was derived from the difference between the mean temperature at the time of sediment-trap sample collection and the late-nineteenth-century mean. This temperature change provides an estimate of the temperature change at each site that is indicative of warming or cooling since approximately the beginning of industrial-era warming. However, given the uncertainty in the age of the sedimentary species assemblages, it is only an approximation of the temperature change since the time of deposition of the sediments. We nevertheless consider this adequate for the purpose of our analysis.

All analyses were done in $\mathrm{R}^{30}$ using packages rioja ${ }^{31}$, reshape $2^{32}$, ggplot $2^{33}$, geosphere $^{34}, \operatorname{readxl}^{35}, \mathrm{Hmisc}^{36}, \operatorname{raster}^{37}, \mathrm{sp}^{38,39}$ and rgdal ${ }^{40}$.

Pre-industrial age of core tops. Marine-sediment archives provide a temporally integrated record of species assemblages. The length of this record depends on the sampling resolution, the sediment accumulation rate and the depth of the layer mixed by bioturbation. The mean age of the core top samples can thus be estimated using the depth solution of a previously published study ${ }^{41}$ and reasonable approximations of the sediment accumulation rate and bioturbation depth. Using an empirical relationship between water depth and Holocene sediment accumulation rate $^{42}$, we calculate a median sediment accumulation rate of the core top samples of 5.9 (interquartile range, $3.8-6.2) \mathrm{cm}$ per thousand years. For bioturbation depth, we use a global average ${ }^{43}$ of $9.8 \pm 4.5 \mathrm{~cm}$. These analyses yield estimated mean ages of the core top sediments of centuries to millennia, warranting their use as an integrated pre-industrial baseline of the planktonic foraminifera assemblages (Extended Data Fig. 1). Note that Extended Data Fig. 1 provides the average age of non-normal distribution of the ages of all sedimentary particles (including foraminifera), such that all sediments also contain foraminifera within the age range of the temperature estimates before marked human influences.

Effect of shell size. Planktonic foraminifera differ in their mean size among species and species assemblages may therefore vary as a function of the analysed size fraction. Whereas the core top samples are all $>150 \mu \mathrm{m}$, our shell flux time series compilation also includes data for sizes $>125 \mu \mathrm{m}$. Even though cold-water species are more abundant in smaller size fractions ${ }^{44}$ and inclusion of data for sizes of
$<150 \mu \mathrm{m}$ would thus bias our results towards cooling rather than warming we nevertheless assessed the influence of size fraction in two ways.

First, we included an additional sensitivity test for the consistency of community change (analogous to Fig. 4) separating the time series by size fraction (Extended Data Fig. 3). Both groups show a change in the community composition consistent with temperature change in the large majority of the cases, which indicates that our results are insensitive to the size fraction of the foraminifera in the sediment-trap time series.

Second, we carried out separate analyses of the coarse- and fine-fraction data from the seven time series for which size-fractionated data are available (CAS, CCG, CCM, CCN, EAS, MBL and WAS; see Extended Data Table 1 for details). In 6 out of these 7 cases, the direction of community change indicated by the assemblages $>125 \mu \mathrm{m}$ is identical to the change estimate from the assemblages $>150 \mu \mathrm{m}$, or indicative of cooling. This means that inclusion of data from time series with the small-size fraction data are much more likely to suggest cooling than warming.

Importantly, the two cases of a consistent shift towards cooler assemblages both pertain to data from the $>150-\mu \mathrm{m}$ fraction (Extended Data Table 1 ) and hence do not reflect size-related biases. The pattern of assemblage change is therefore a robust, if conservative, estimate of the change in planktonic foraminifera community change.

Effect of choice of temperature dataset. Historical sea-surface temperature data that predate the onset of large-scale shipboard measurements and satellite observations are associated with uncertainty, which is reflected in the differences between different data products. To evaluate the effect of the choice of temperature data product, we also conducted our analysis using ERSST version 5 data ${ }^{45}$. Compared to the HadISST data, ERSST data have a coarse resolution $\left(2^{\circ} \times 2^{\circ}\right.$ compared to $1 \times 1^{\circ}$ ), but the data extend back to $\mathrm{AD} 1854$, offering the possibility to obtain a better estimate of industrial-era warming. The ERSST v.5 data (also integrated over 30 years, but shifted backwards to AD 1854 to make full use of the longer temporal extent of the ERSST data) show generally less temperature change compared to HadISST $^{46}$. However, our results are largely insensitive to the data product used and the two sea-surface temperature products reveal the same patterns. The scaling between dissimilarity and temperature change is similar, albeit with a larger uncertainty for ERSST (Extended Data Fig. 4a), and the changes in species community are also largely consistent with the temperature change estimated from the ERRST data (Extended Data Fig. 4b). This makes us confident that the observed patterns in the change in species communities are robust.

Reporting summary. Further information on research design is available in the Nature Research Reporting Summary linked to this paper.

\section{Data availability}

The ForCenS core top planktonic foraminifera dataset is available at Pangaea (https://doi.org/10.1594/PANGAEA.873570) and the HadISST data are available from the UK Met Office (https://www.metoffice.gov.uk/hadobs/hadisst/). NOAA ERSST v. 5 data were provided by the NOAA/OAR/ESRL PSD (https://www.esrl. noaa.gov/psd/). Taxonomically harmonized shell flux data are available at https:// doi.org/10.5281/zenodo.2638013.

\section{Code availability}

Code is available at https://doi.org/10.5281/zenodo.2638013.

27. Jonkers, L. \& Kučera, M. Global analysis of seasonality in the shell flux of extant planktonic Foraminifera. Biogeosciences 12, 2207-2226 (2015)

28. Prell, W. The Stability of Low-Latitude Sea-Surface Temperatures, an Evaluation of the CLIMAP Reconstruction with Emphasis on the Positive SST Anomalies. Report No. TR025 (US Department of Energy, 1985).

29. Darling, K. F. \& Wade, C. M. The genetic diversity of planktic foraminifera and the global distribution of ribosomal RNA genotypes. Mar. Micropaleontol. 67, 216-238 (2008)

30. R Core Team. R: A Language and Environment for Statistical Computing. https:// www.R-project.org/ (R Foundation for Statistical Computing, 2016).

31. Juggins, S. rioja: Analysis of Quaternary Science Data. R package version 0.9-15.1 http://cran.r-project.org/package=rioja (2017).

32. Wickham, H. Reshaping data with the reshape package. J. Stat. Softw. 21, 1-20 (2007).

33. Wickham, H. ggplot2: Elegant Graphics for Data Analysis (Springer, 2016).

34. Hijmans, R. J., Williams, E. \& Vennes, C. geosphere: Spherical Trigonometry. R package version 1.5-7 https://CRAN.R-project.org/package=geosphere (2017)

35. Wickham, H. \& Bryan, J. readxl: Read Excel Files. R package version 1.1.0 https://CRAN.R-project.org/package=readxl (2018).

36. Harrell, F. E. Jr. Hmisc: Harrell Miscellaneous. R package version 4.1-1 https://CRAN.R-project.org/package=Hmisc (2018).

37. Hijmans, R. J. et al. raster: Geographic Data Analysis and Modeling. R package version 2.6-7. https://CRAN.R-project.org/package=raster (2017).

38. Pebesma, E. J. \& Bivand, R. S. Classes and methods for spatial data in R. $R$ News 5, 9-13 (2005). 
39. Bivand, R. S., Pebesma, E. \& Gómez-Rubio, V. Applied Spatial Data Analysis with R (Springer, 2008).

40. Bivand, R. et al. rgdal: Bindings for the 'Geospatial' Data Abstraction Library. R package version 1.3-1 https://CRAN.R-project.org/package=rgdal (2018)

41. Berger, W. H. \& Heath, G. R. Vertical mixing in pelagic sediments. J. Mar. Res. 26 134-143 (1968).

42. Burwicz, E. B., Rüpke, L. H. \& Wallmann, K. Estimation of the global amount of submarine gas hydrates formed via microbial methane formation based on numerical reaction-transport modeling and a novel parameterization of Holocene sedimentation. Geochim. Cosmochim. Acta 75, 4562-4576 (2011)

43. Boudreau, B. P. Mean mixed depth of sediments: the wherefore and the why. Limnol. Oceanogr. 43, 524-526 (1998).

44. Al-Sabouni, N., Kucera, M. \& Schmidt, D. N. Vertical niche separation control of diversity and size disparity in planktonic foraminifera. Mar. Micropaleontol. 63, 75-90 (2007)

45. Huang, B. et al. NOAA Extended Reconstructed Sea Surface Temperature (ERSST). Version 5 https://doi.org/10.7289/V5T72FNM (NOAA National Centers for Environmental Information, 2017).

46. Huang, B. et al. Further exploring and quantifying uncertainties for extended reconstructed sea surface temperature (ERSST) version 4 (v4). J. Clim. 29, 3119-3142 (2016).

47. Asahi, H. \& Takahashi, K. A 9-year time-series of planktonic foraminifer fluxes and environmental change in the Bering Sea and the central subarctic Pacific Ocean, 1990-1999. Prog. Oceanogr. 72, 343-363 (2007).

48. Deuser, W. G. \& Ross, E. H. Seasonally abundant planktonic foraminifera of the Sargasso Sea; succession, deep-water fluxes, isotopic compositions, and paleoceanographic implications. J. Foraminiferal Res. 19, 268-293 (1989).

49. Deuser, W. G., Ross, E. H., Hemleben, C. \& Spindler, M. Seasonal changes in species composition, numbers, mass, size, and isotopic composition of planktonic foraminifera settling into the deep Sargasso Sea. Palaeogeogr. Palaeoclimatol. Palaeoecol. 33, 103-127 (1981)

50. Northcote, L. C. \& Neil, H. L. Seasonal variations in foraminiferal flux in the Southern Ocean, Campbell Plateau, New Zealand. Mar. Micropaleontol. 56, 122-137 (2005).

51. Guptha, M. V. S., Curry, W. B., Ittekkot, V. \& Muralinath, A. S. Seasonal variation in the flux of planktic Foraminifera; sediment trap results from the Bay of Bengal, northern Indian Ocean. J. Foraminiferal Res. 27, 5-19 (1997).

52. Žarić, S., Donner, B., Fischer, G., Mulitza, S. \& Wefer, G. Sensitivity of planktic foraminifera to sea surface temperature and export production as derived from sediment trap data. Mar. Micropaleontol. 55, 75-105 (2005).

53. Reuter, R. T., Jonkers, L. \& Kucera, M. Planktonic foraminifera shell flux data from sediment trap CB-3. PANGAEA https://doi.org/10.1594/ PANGAEA.899732 (2016).

54. Ortiz, J. D. \& Mix, A. C. The spatial distribution and seasonal succession of planktonic foraminifera in the California Current off Oregon, September 1987 - September 1988. Geol. Soc. Lond. Spec. Publ. 64, 197-213 (1992).

55. Jensen, S. Planktische Foraminiferen im Europaischen Nordmeer: Verbreitung und Vertikalfluss sowie ihre Entwicklung wahrend der letzten 15000 Jahre. PhD thesis, Univ. Kiel (1998).

56. Poore, R. Z., Tedesco, K. A. \& Spear, J. W. Seasonal flux and assemblage composition of planktic foraminifers from a sediment-trap study in the northern Gulf of Mexico. J. Coast. Res. 63, 6-19 (2013).

57. Reynolds, C. E., Richey, J. N. \& Poore, R. Z. Seasonal Flux and Assemblage Composition of Planktic Foraminifera from the Northern Gulf of Mexico, 2008-2012. US Geological Survey Open-File Report 2013-1243 https:// doi.org/10.3133/ofr20131243 (USGS, 2013).

58. Jonkers, L., Reynolds, C. E., Richey, J. \& Hall, I. R. Lunar periodicity in the shell flux of planktonic foraminifera in the Gulf of Mexico. Biogeosciences $\mathbf{1 2}$. 3061-3070 (2015).
59. Wolfteich, C. M. Sattelite-Derived Sea Surface Temperature, Mesoscale Variability, And Foraminiferal Production in the North Atlantic. MSc thesis, MIT and WHOI (1994).

60. Jonkers, L., Brummer, G.-J. A., Peeters, F. J. C., van Aken, H. M. \& De Jong, M. F. Seasonal stratification, shell flux, and oxygen isotope dynamics of left-coiling $N$. pachyderma and T. quinqueloba in the western subpolar North Atlantic. Paleoceanography 25, PA2204 (2010).

61. Jonkers, L., van Heuven, S., Zahn, R. \& Peeters, F. J. C. Seasonal patterns of shell flux, $\delta^{18} \mathrm{O}$ and $\delta^{13} \mathrm{C}$ of small and large N. pachyderma (s) and G. bulloides in the subpolar North Atlantic. Paleoceanography 28, 164-174 (2013).

62. Reuter, R. T., Jonkers, L., Brummer, G. J. \& Kucera, M. Planktonic foraminifera shell flux data from sediment trap IRM-1. PANGAEA https://doi.org/10.1594/ PANGAEA.899733 (2018).

63. Mohtadi, M. et al. Low-latitude control on seasonal and interannual changes in planktonic foraminiferal flux and shell geochemistry off south Java: A sediment trap study. Paleoceanography 24, PA1201 (2009).

64. Rigual-Hernández, A. S., Sierro, F. J., Bárcena, M. A., Flores, J. A. \& Heussner, S. Seasonal and interannual changes of planktic foraminiferal fluxes in the Gulf of Lions (NW Mediterranean) and their implications for paleoceanographic studies: two 12-year sediment trap records. Deep Sea Res. 66, 26-40 (2012).

65. Donner, B. \& Wefer, G. Flux and stable isotope composition of Neogloboquadrina pachyderma and other planktonic foraminifers in the Southern Ocean (Atlantic sector). Deep Sea Res. 41, 1733-1743 (1994).

66. Storz, D., Schulz, H., Waniek, J. J., Schulz-Bull, D. E. \& Kučera, M. Seasonal and interannual variability of the planktic foraminiferal flux in the vicinity of the Azores Current. Deep Sea Res. 56, 107-124 (2009).

67. Kuroyanagi, A., Kawahata, H., Nishi, H. \& Honda, M. C. Seasonal changes in planktonic foraminifera in the northwestern North Pacific Ocean: sediment trap experiments from subarctic and subtropical gyres. Deep Sea Res. 49, 5627-5645 (2002).

68. Sagawa, T., Kuroyanagi, A., Irino, T., Kuwae, M. \& Kawahata, H. Seasonal variations in planktonic foraminiferal flux and oxygen isotopic composition in the western North Pacific: implications for paleoceanographic reconstruction. Mar. Micropaleontol. 100, 11-20 (2013).

69. Alderman, S. E. Planktonic Foraminifera in the Sea of Okhotsk: Population and Stable Isotopic Analysis from a Sediment Trap. MSc thesis, MIT and WHOI (1996).

70. Sautter, L. R. \& Thunell, R. C. Seasonal succession of planktonic foraminifera; results from a four-year time-series sediment trap experiment in the Northeast Pacific. J. Foraminiferal Res. 19, 253-267 (1989).

71. King, A. L. \& Howard, W. R. Planktonic foraminiferal flux seasonality in Subantarctic sediment traps: a test for paleoclimate reconstructions. Paleoceanography 18, 1019 (2003)

72. Curry, W. B., Ostermann, D. R., Guptha, M. V. S. \& Ittekkot, V. Foraminiferal production and monsoonal upwelling in the Arabian Sea: evidence from sediment traps. Geol. Soc. Lond. Spec. Publ. 64, 93-106 (1992).

73. Mohiuddin, M. M., Nishimura, A., Tanaka, Y. \& Shimamoto, A. Regional and interannual productivity of biogenic components and planktonic foraminiferal fluxes in the northwestern Pacific Basin. Mar. Micropaleontol. 45, 57-82 (2002).

74. Mohiuddin, M. M., Nishimura, A. \& Tanaka, Y. Seasonal succession, vertical distribution, and dissolution of planktonic foraminifera along the Subarctic Front: implications for paleoceanographic reconstruction in the northwestern Pacific. Mar. Micropaleontol. 55, 129-156 (2005).

75. Xiang, R. et al. Seasonal flux variability of planktonic foraminifera during 2009-2011 in a sediment trap from Xisha Trough, South China Sea. Aquat. Ecosyst. Health Manage. 18, 403-413 (2015). 


\section{RESEARCH LETTER}

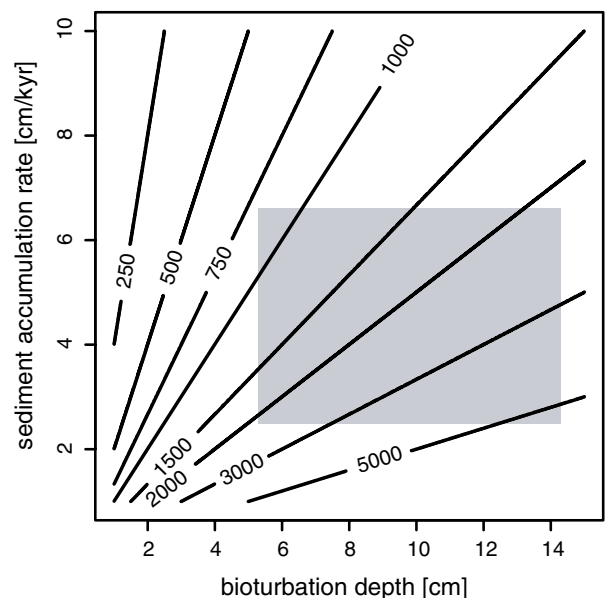

Extended Data Fig. 1 | Pre-industrial age of the sedimentary samples. Mean age in years of core top sediment estimate using the depth solution of a previous study ${ }^{41}$ (contours). The grey box denotes the likely average ages of the core top sediments based on our best estimate of sediment accumulation rate (in $\mathrm{cm}$ per 1,000 years (kyr)) and bioturbation depth. Irrespective of the sampling date (mostly pre-1980), the average sedimentary species composition predates the Anthropocene. 


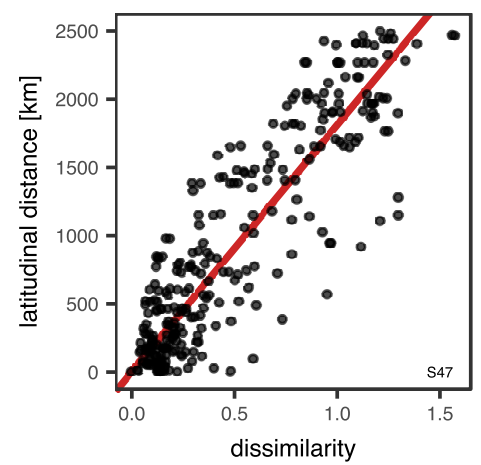

Extended Data Fig. 2 | Linear regression between dissimilarity and latitudinal distance in the sedimentary species assemblages. The relationship (shown in red) is used to estimate the latitudinal displacement based on the dissimilarity between the modern and pre-industrial species composition. Example for time series S47 from the south of New Zealand (Extended Data Table 1). 


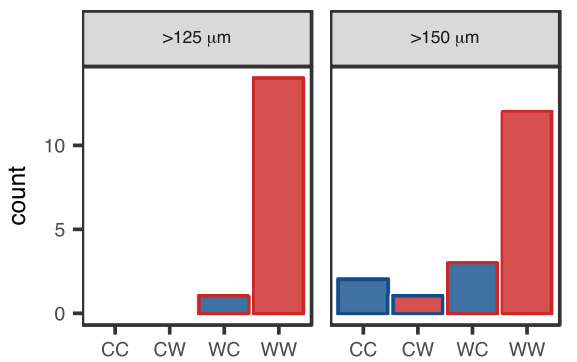

Extended Data Fig. 3 | Insensitivity of planktonic foraminifera assemblage change to size fraction. The direction of change for planktonic foraminifera species communities (warming or cooling) was inferred from sediment-trap time series for which the samples were larger than $125 \mu \mathrm{m}$ and larger than $150 \mu \mathrm{m}$. Colours and symbols are as in Fig. 3b. W and C indicate warming and cooling, respectively, with the first letter indicating the historical change and the second the change as indicated by the species composition. Both small and large shell sizes are dominated by a change in the species community that is consistent with the direction of historical change in temperatures. The observed pattern is thus insensitive to the inclusion of sediment-trap time series that used a slightly smaller size fraction than the sediment samples. 

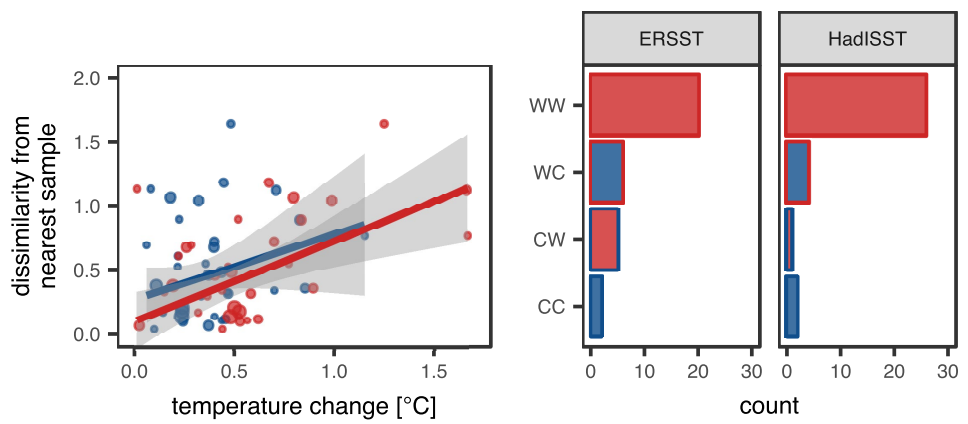

ERSST

HadISST

Extended Data Fig. $4 \mid$ Assessing uncertainty in the historical change in temperatures by comparing the HadISST and ERSST temperature products. a, Comparison of the relationships between the historical change in temperature and the difference between the modern and sedimentary species composition (based on linear regression weighted to the duration of the time series; see also Fig. 2a). The relationship has a similar slope for both sea-surface temperature products, even though the relationship based on ERSST data has a larger uncertainty. Shaded error envelopes show 95\% confidence intervals of the regression. $\mathbf{b}$, Histograms of consistency and direction of changes in the species communities

(Fig. 3a). The pattern of change is broadly similar for both products, which indicates that although the observations are to some degree sensitive to the uncertainty in the historical change in temperatures, they are largely consistent between the two datasets. 
RESEARCH LETTER

Extended Data Table 1 | Sediment-trap time series used to determine modern species compositions

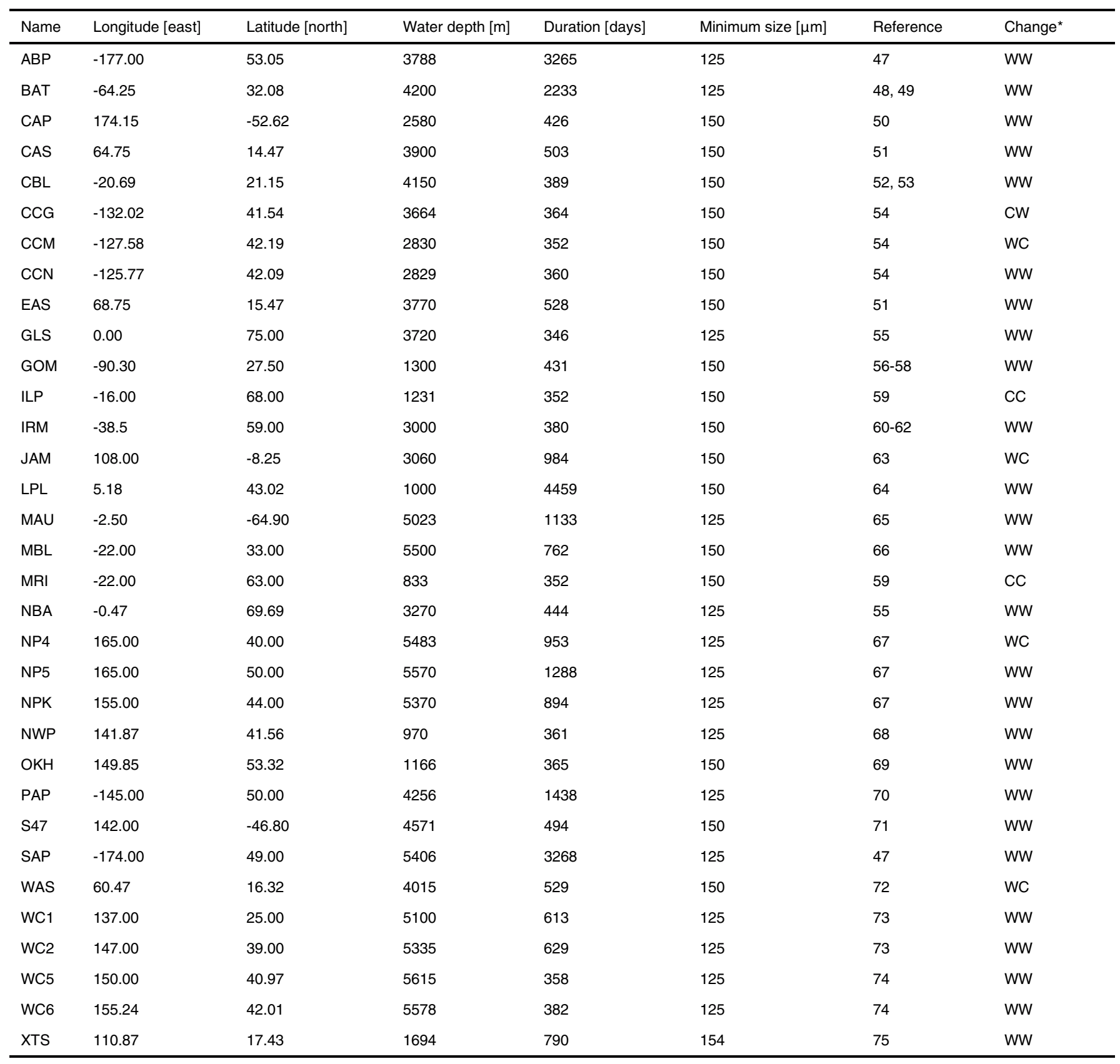

Data were obtained from previous studies ${ }^{47-75}$.

*The first letter refers to the historical temperature change, and the second letter refers to the change indicated by the change in the species composition. W and $\mathrm{C}$ indicate warming and cooling, respectively. 


\section{nature research}

Corresponding author(s): Lukas Jonkers

Last updated by author(s): Mar 21, 2019

\section{Reporting Summary}

Nature Research wishes to improve the reproducibility of the work that we publish. This form provides structure for consistency and transparency in reporting. For further information on Nature Research policies, see Authors \& Referees and the Editorial Policy Checklist.

\section{Statistics}

For all statistical analyses, confirm that the following items are present in the figure legend, table legend, main text, or Methods section.

n/a Confirmed

$\bigotimes$ The exact sample size $(n)$ for each experimental group/condition, given as a discrete number and unit of measurement

Х $\square$ A statement on whether measurements were taken from distinct samples or whether the same sample was measured repeatedly

$\checkmark$ The statistical test(s) used AND whether they are one- or two-sided

Only common tests should be described solely by name; describe more complex techniques in the Methods section.

\ $\square$ A description of all covariates tested

Х $\square$ A description of any assumptions or corrections, such as tests of normality and adjustment for multiple comparisons

A full description of the statistical parameters including central tendency (e.g. means) or other basic estimates (e.g. regression coefficient)

$\triangle$ AND variation (e.g. standard deviation) or associated estimates of uncertainty (e.g. confidence intervals)

For null hypothesis testing, the test statistic (e.g. $F, t, r$ ) with confidence intervals, effect sizes, degrees of freedom and $P$ value noted

Give $P$ values as exact values whenever suitable.

Х $\square$ For Bayesian analysis, information on the choice of priors and Markov chain Monte Carlo settings

Х $\square$ For hierarchical and complex designs, identification of the appropriate level for tests and full reporting of outcomes

$\square$ Estimates of effect sizes (e.g. Cohen's $d$, Pearson's $r$ ), indicating how they were calculated

Our web collection on statistics for biologists contains articles on many of the points above.

\section{Software and code}

\section{Policy information about availability of computer code}

Data collection

no software used for collection

Data analysis

R version 3.5; publicly available packages listed in methods

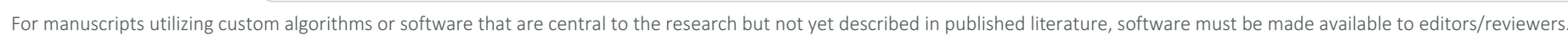
We strongly encourage code deposition in a community repository (e.g. GitHub). See the Nature Research guidelines for submitting code \& software for further information.

\section{Data}

Policy information about availability of data

All manuscripts must include a data availability statement. This statement should provide the following information, where applicable:

- Accession codes, unique identifiers, or web links for publicly available datasets

- A list of figures that have associated raw data

- A description of any restrictions on data availability

The ForCens core top planktonic foraminifera data set is available at Pangaea (https://doi.pangaea.de/10.1594/PANGAEA.873570) and the HadISST data are available from the UK Met Office (https://www.metoffice.gov.uk/hadobs/hadisst/). NOAA ERSST V5 data were provided by the NOAA/OAR/ESRL PSD, Boulder, Colorado, USA, from their Web site at https://www.esrl.noaa.gov/psd/. Code and taxonomically harmonised shell flux data will be made available on github/zenodo. 
Please select the one below that is the best fit for your research. If you are not sure, read the appropriate sections before making your selection.

Life sciences

\section{Ecological, evolutionary \& environmental sciences study design}

All studies must disclose on these points even when the disclosure is negative.

Study description

We compare species communities (relative abundances) of fossil and modern marine microplankton (planktonic foraminifera) using commonly used dissimilarity metrics. Data on the modern species communities is derived from sediment traps and fluxes have been integrated to allow comparison with the fossil data. The approach is described in the method section.

Research sample

We used published data only; fossil species community data from Siccha, M., and Kucera, M.: ForCenS, a curated database of planktonic foraminifera census counts in marine surface sediment samples, Scientific Data, 4, 170109, 10.1038/sdata.2017.109, 2017. We chose this dataset as it is the most extensive and most recent compilation to date.

Sediment trap data were compiled from literature (see Jonkers, L., and Kučera, M.: Global analysis of seasonality in the shell flux of extant planktonic Foraminifera, Biogeosciences, 12, 2207-2226, 10.5194/bg-12-2207-2015, 2015.). We have updated this compilation in order to include all (to the best of our knowledge, see also reviews) sediment trap time series. A full list is provided in the method section of the manuscript

Sampling strategy

We used compiled literature data

Data collection

We used previously compiled and published data, collection methods are described in the relevant publications listed in the method section

Timing and spatial scale We used previously published data. The fossil data are from surface deep sea sediments sampled over the past decades (age assessed in manuscript) and the modern data from moored sediment traps are from over 30 different studies since 1978. Both data sets are global in their extent

Data exclusions

Criteria for inclusion in our shell flux compilation were predetermined and 1) a minimum time series length of 345 days in order reduce the effect of seasonality; 2) complete taxonomic resolution in order to sensibly compare plankton and sediment species assemblages and 3) no indication of resuspension (i.e. the presence of benthic foraminifera) to make sure that we are looking at a primary signal.

Reproducibility no experiments conducted

Randomization

no experiments conducted; not applicable to observational time series from sediment traps used here

Blinding

no experiments conducted; not applicable to observational time series from sediment traps used here

Did the study involve field work? $\square$ Yes $\$ No

\section{Reporting for specific materials, systems and methods}

We require information from authors about some types of materials, experimental systems and methods used in many studies. Here, indicate whether each material, system or method listed is relevant to your study. If you are not sure if a list item applies to your research, read the appropriate section before selecting a response.

Materials \& experimental systems

$\mathrm{n} / \mathrm{a}$ Involved in the study

Methods

\ $\square$ Antibodies

Х $\square$ Eukaryotic cell lines

n/a Involved in the study

Х $\square$ ChIP-seq

Х $\square$ Palaeontology

Х $\square$ Flow cytometry

Х $\square$ Animals and other organisms

X $\square$ MRI-based neuroimaging

Х $\square$ Human research participants

$\bigotimes \square$ Clinical data 